\title{
Correlation analysis of stress and family function and coping modes in pregnant women with pregnancy-induced hypertension syndrome
}

\author{
Shaoning Xing ${ }^{1 \#}$, Ling Wan ${ }^{2 \#}$, Aizhen Fu ${ }^{1}$, Wei Liu ${ }^{1}$, Lihui Lin ${ }^{2}$, Caiyu Wang ${ }^{2}$, Jing Wang ${ }^{3}$, \\ Guangchi Huang ${ }^{3}$, Meirong $\mathrm{Lu}^{3}$ \\ ${ }^{1}$ Department of Obstetrics and Gynecology, Haikou Hospital of the Maternal and Child Health, Haikou, China; ${ }^{2}$ Department of Obstetrics and \\ Gynecology, Hainan West Central Hospital, Danzhou, China; ${ }^{3}$ Department of Obstetrics and Gynecology, Hainan Modern Women and Children's \\ Hospital, Haikou, China \\ Contributions: (I) Conception and design: S Xing, L Wan, M Lu; (II) Administrative support: A Fu; (III) Provision of study materials or patients: S \\ Xing, L Wan, M Lu; (IV) Collection and assembly of data: S Xing; (V) Data analysis and interpretation: M Liu; (VI) Manuscript writing: All authors; \\ (VII) Final approval of manuscript: All authors. \\ "These authors contributed equally to this work. \\ Correspondence to: Meirong Lu. Department of Obstetrics and Gynecology, Hainan Modern Women and Children's Hospital, Haikou 570100, China. \\ Email: lumeirong4777@163.com.
}

Background Pregnancy-induced hypertension is a common complication in obstetrics and an important
cause of maternal death. We explored the correlations among stress, family function and coping mode in
women with pregnancy-induced hypertension syndrome.
Methods: A total of 58 pregnant women with pregnancy-induced hypertension syndrome were included
in the study. The perceived stress scale (PSS), family assessment device (FAD), and medical coping modes
questionnaire (MCMQ) were used to assess stress level, family function, and coping mode, respectively.

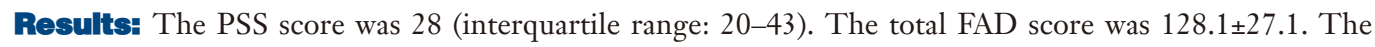
subscale scores were problem-solving, affective responsiveness, communication, roles, behavior control, affective involvement, and general function, in order of decreasing score. Significant correlations were noted between PSS score and total FAD score, affective responsiveness, problem-solving, communication, roles, affective involvement, and behavior control (all $\mathrm{P}<0.05$ ). PSS score was significantly correlated with "Escape" $(\mathrm{P}=0.016)$ and "Yield" $(\mathrm{P}<0.001)$ in the MCMQ. Single-factor analysis showed that education level, average household income, and FAD total score were significantly different in those with a low or high PSS score. Logistic regression indicated the FAD total score as an independent factor for the PSS score.

Conclusions: Women with pregnancy-induced hypertension syndrome with a high PSS score tended to adopt the "Escape" and "Yield" coping modes. Family function integrity is essential for reducing PSS scores.

Keywords: Coping modes; family function; pregnancy-induced hypertension syndrome; stress

Submitted Sep 09, 2021. Accepted for publication Oct 02, 2021.

doi: 10.21037/apm-21-2662

View this article at: https://dx.doi.org/10.21037/apm-21-2662

\section{Introduction}

Pregnancy-induced hypertension is a group of obstetric clinical and common diseases, including preeclampsia, eclampsia, pregnancy with chronic hypertension, and chronic hypertension with preeclampsia. Studies have shown that gestational hypertension accounts for about $5-10 \%$ of all pregnancies (1). An epidemiological survey of 5,521 pregnant women aged 20-40 in the United States found that $7.7 \%$ suffered from hypertension 
during pregnancy (2), and it is the second leading cause of maternal death in China. At present, the specific cause of hypertension in pregnancy is not clear, and it may be related to factors such as abnormal trophoblast cell invasion, immune regulation disorders, vascular endothelial damage, genetics, and nutrition. Pregnancyinduced hypertension not only leads to adverse pregnancy outcomes but also has a significant psychological effect on the pregnant woman. Studies have shown that pregnant women with gestational hypertension are in a state of stress. Their risk of postpartum depression, anxiety, and post-traumatic stress disorder syndrome is significantly higher than that of unaffected pregnant women (3). Family function refers to the emotional connection, family rules, family communication and the effectiveness of responding to external events in the family system. Perfect family function not only helps to ease maternal anxiety but also maintains family harmony, thus promoting maternal physical and mental wellbeing. For example, a cross-sectional study in Hengyang showed that the family dysfunction was closely related to maternal depression (4). In contrast, a perfect family function can help pregnant women make full use of medical resources to reduce their stress and adverse pregnancy events (5). A study showed that the psychological factors, family and social support of pregnant women are related to the occurrence of hypertension during pregnancy (6). Affected pregnant women may adopt different coping modes, such as "Escape", "Face", or "Yield", in response to stress. In this study, we explored the correlations between the stress level of pregnant women with pregnancy-induced hypertension and their family function and coping mode to provide more targeted diagnosis, treatment, and nursing care for pregnant women with pregnancy-induced hypertension. We present the following article in accordance with the STROBE reporting checklist (available at https://dx.doi. org/10.21037/apm-21-2662).

\section{Methods}

\section{Study subjects}

From January 2019 to December 2020, 58 pregnant women with pregnancy-induced hypertension were enrolled. The inclusion criteria were: (I) able to understand the content of the study and agree to participate in it; (II) no additional stressors other than hypertensive disorder complicating pregnancy. The exclusion criteria were: (I) unable to read or understand the content of this study, and so informed consent was not available; (II) severe organ dysfunction, such as liver failure, severe thrombocytopenia. (III) The patient has non-pregnancy-related hypertensive factors such as primary hypertension and secondary hypertension. All procedures performed in this study involving human participants were in accordance with the Declaration of Helsinki (as revised in 2013). The study was approved by the Ethics Committee of Haikou Hospital of the Maternal and Child Health (No. 2018042) and informed consent was given by all the patients.

\section{Survey tools}

Questionnaires were distributed by 2 medical staff trained in our department. When necessary, explain the specific meaning of each item to the survey object, and the survey object will fill in and collect it on the spot. Excluding missing items and invalid questionnaires, 58 final questionnaires were valid questionnaires. The women's general information, such as disease diagnosis, age, gestational age, primipara/multipara, education level, monthly family income, medical expenses payment, etc., was collected by a self-administered survey.

\section{Evaluation of stress level}

A subjective stress scale, the perceived stress scale (PSS), was used to evaluate the emotional stress level associated with pregnancy-induced hypertension. Research shows that the Chinese version of PSS has high reliability and validity (7). The correlation coefficient of Cronbach $\alpha$ is 0.91 , and the retest correlation coefficient is 0.69 .

\section{Family function}

The Chinese version of the family assessment device (FAD) was used to evaluate the family function of the pregnant women. There are 60 questions in the latest version, covering seven dimensions of family function: solution, communication, role, emotional response, emotional intervention, behavior control, and general function. The higher the score, the more serious is the family dysfunction.

\section{Assessment of the response to stress}

The Chinese version of the medical coping modes 
Table 1 General information of the study group of pregnant women $(\mathrm{n}=58)$

\begin{tabular}{lc}
\hline Variables & Count/mean \\
\hline Age (years), mean \pm SD & $26.7 \pm 3.7$ \\
Gestational age (weeks), mean \pm SD & $32.9 \pm 2.4$ \\
Parity, $\mathrm{n}(\%)$ & \\
Primipara & $46(79.3)$ \\
Multipara & $12(20.7)$ \\
Education level, $\mathrm{n}(\%)$ & \\
Junior high school or below & $8(13.8)$ \\
High school & $24(41.4)$ \\
University or postgraduate & $26(44.8)$ \\
Average monthly household income (RMB), $\mathrm{n}(\%)$ & \\
$<5,000$ & $7(12.1)$ \\
5,000-10,000 & $26(44.8)$ \\
$>10,000$ & $25(43.1)$ \\
Payment of medical expenses, $\mathrm{n}(\%)$ & $53(91.4)$ \\
Medical insurance & \\
Self-funded & \\
\hline
\end{tabular}

$\mathrm{SD}$, standard deviation.

questionnaire (MCMQ) was used to assess how pregnant women respond to stress (8). The MCMQ Chinese edition consists of 20 entries, covering three dimensions, "Face" (8 entries), "Escape" (7 entries), and "Yield" (8 entries), each with a score of $1-4$. The higher the score per dimension, the more frequently the patient responds to stress.

\section{Statistical analysis}

SPSS 22.0 was utilized for data processing and statistical analysis. General information about the patient was expressed as mean \pm standard deviation or rate/percentage. Because the PSS scores were not normally distributed, the correlation between the PSS score and the family function dimensions was calculated using Spearman-related calculations. According to the median PSS score, the subjects were divided into low-stress and high-stress groups. The risk factors affecting stress levels were identified through single-factor and multifactor analysis. A two-sided $\mathrm{P}<0.05$ indicated statistical difference.

\section{Results}

\section{General information of the pregnant women (Table 1)}

The mean age and gestational age of the 58 pregnant women with pregnancy-induced hypertension were $26.7 \pm 3.7$ years and $32.9 \pm 2.4$ weeks, respectively. Most of the patients were primipara, most of whom had graduated from high school, university, or postgraduate. The average monthly family income was 5-10 k RMB and $>10 \mathrm{k}$ RMB.

\section{Stress level, family function and coping modes}

As shown in Table 2, the total score of family function (FAD) of the pregnant women included in the study was $128.1 \pm 27.1$, and the average score of items was $2.14 \pm 0.45$. The average scores of FAD in decreasing order were problem-solving, emotional response, communication, role, behavior control, emotional intervention, and general function. The median stress level (PSS) of the pregnant women was 28 , and the interquartile range was $20-43$. The scores of coping mode (MCMQ) were 20.4 \pm 5.7 for "Face", $18.8 \pm 4.8$ for "Escape", and 21.3 \pm 5.0 for "Yield".

\section{Correlation analysis of stress level, family function and coping mode (Table 3)}

The PSS score significantly correlated with total FAD score, emotional response, problem-solving, communication, role, emotional intervention, and behavior control. The correlation between the PSS score and the total score of FAD was the largest (rho $=0.746, \mathrm{P}<0.001)$. There was no significant correlation between the PSS score and the total function of the FAD subscale.

As shown in Figure 1, there was no significant correlation between PSS score and the "Face" coping mode in the MCMQ (rho $=-0.144, \mathrm{P}=0.28$ ), between the PSS score and "Escape" coping mode (rho $=0.314, \mathrm{P}=0.016$ ), or the "Yield" coping mode (rho $=0.507, \mathrm{P}<0.001)$.

\section{Single-factor analysis of stress level of the pregnant women}

According to the median PSS score (28 points), the pregnant women were divided into low-stress group and high-stress group. The univariate analysis is shown in Table 4. The results showed that there were significant differences between the groups in education level, average 
Table 2 Stress level (PSS), family function (FAD), and coping mode (MCMQ) scores of the pregnant women

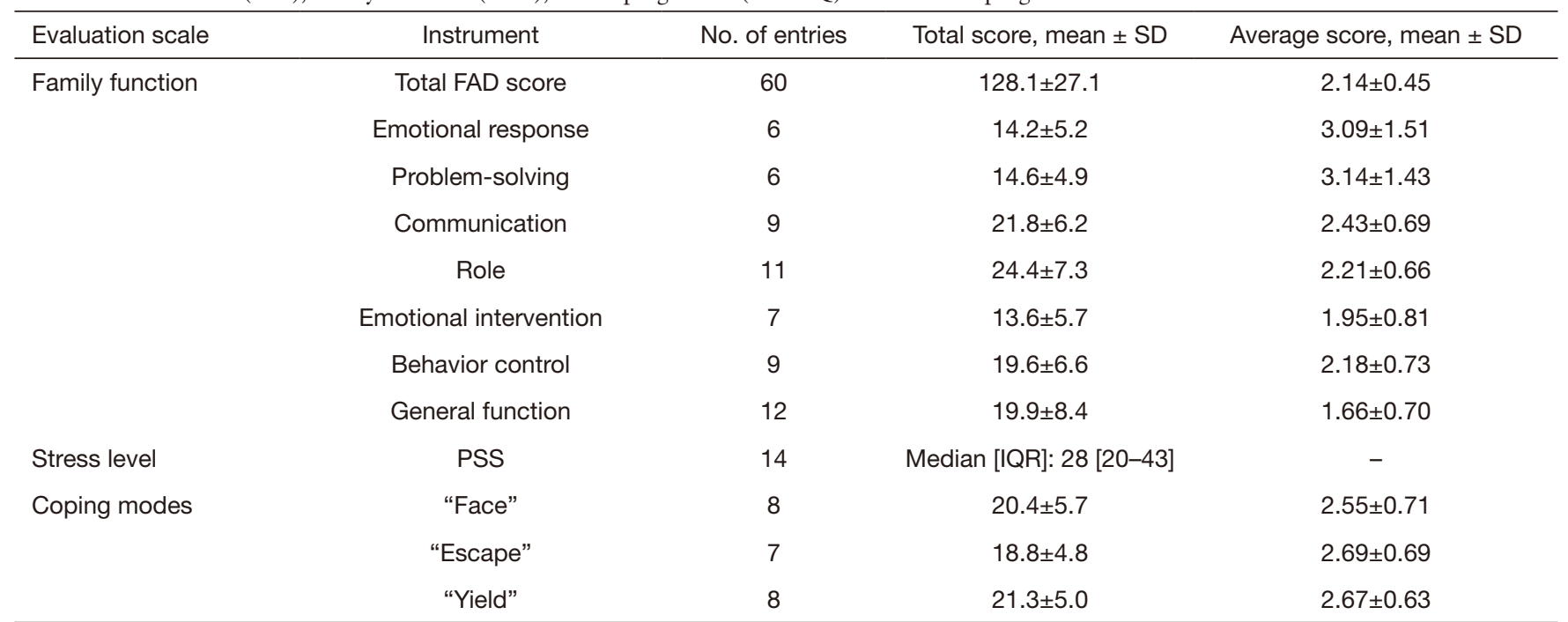

PSS, perceived stress scale; FAD, family assessment device; MCMQ, medical coping modes questionnaire; SD, standard deviation; IQR, interquartile range.

Table 3 Correlation between stress level (PSS score) and family function (total FAD score) and each subscale score (rho, n=58)

\begin{tabular}{lccccccc}
\hline Variables Total FAD score & $\begin{array}{c}\text { Emotional } \\
\text { response }\end{array}$ & Problem-solving & Communication & Role & $\begin{array}{c}\text { Emotional } \\
\text { Intervention }\end{array}$ & $\begin{array}{c}\text { Behavior } \\
\text { control }\end{array}$ & $\begin{array}{c}\text { General } \\
\text { function }\end{array}$ \\
\hline PSS & $0.746^{\star \star *}$ & $0.612^{\star \star \star}$ & $0.491^{\star \star \star}$ & $0.405^{\star \star *}$ & $0.512^{\star \star *}$ & $0.673^{\star \star \star}$ & $0.419^{\star \star}$ \\
\hline
\end{tabular}

${ }^{* \star}, \mathrm{P}<0.01 ;{ }^{* * \star}, \mathrm{P}<0.001$. PSS, perceived stress scale; FAD, family assessment device.
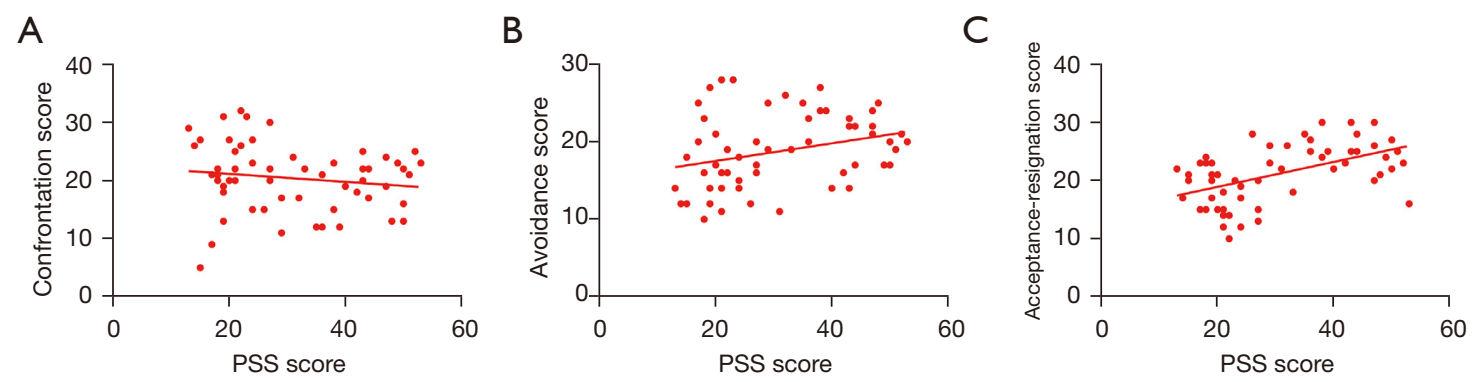

Figure 1 Correlation between perceived stress scale (PSS) score and coping modes: (A) Face; (B) Escape; (C) Yield.

monthly family income, and total FAD score; the low-stress group had a higher education level, higher family income, and lower total FAD score than the high-stress group.

\section{Analysis of multiple factors influencing the stress level of the pregnant women (Table 5)}

Binary logistic regression analysis showed that the total FAD score was still an independent risk factor for pregnant women with pregnancy-induced hypertension. In contrast, the education level and average monthly family income of pregnant women were not statistically significant after multivariate analysis.

\section{Discussion}

Pregnancy-induced hypertension is a common cause of severe adverse pregnancy outcomes. Active fetal testing, 
Table 4 Comparison of relevant data of low and high stress level groups

\begin{tabular}{|c|c|c|c|c|}
\hline Variables & Low stress level $(n=29)$ & High stress level $(n=29)$ & Inspection value & $\mathrm{P}$ \\
\hline Gestational week, mean \pm SD & $33.0 \pm 2.2$ & $32.7 \pm 2.7$ & 0.43 & 0.67 \\
\hline Parity & & & 0.42 & 0.52 \\
\hline Primipara & 24 & 22 & & \\
\hline Education level & & & 8.0 & 0.02 \\
\hline Junior high school or below & 4 & 4 & & \\
\hline High school & 7 & 17 & & \\
\hline University or postgraduate & 18 & 8 & & \\
\hline $5,000-10,000$ & 8 & 18 & & \\
\hline$>10,000$ & 18 & 7 & & \\
\hline Payment of medical expenses & & & 0.22 & $>0.99$ \\
\hline Medical insurance & 27 & 26 & & \\
\hline Self-funded & 2 & 3 & & \\
\hline Total FAD score, mean \pm SD & $108.6 \pm 19.7$ & $147.6 \pm 17.9$ & -7.89 & $<0.001$ \\
\hline
\end{tabular}

$\mathrm{SD}$, standard deviation; FAD, family assessment device.

Table 5 Multivariate regression analysis of stress levels of pregnant women with pregnancy-induced hypertension

\begin{tabular}{lcccc}
\hline Variables & $\mathrm{B}$ & $\operatorname{Exp}(\mathrm{B})$ & $95 \% \mathrm{Cl}$ & $\mathrm{P}$ \\
\hline Education & -0.278 & 0.757 & $0.238-2.409$ & 0.64 \\
Monthly income & -0.645 & 0.525 & $0.124-2.225$ & 0.38 \\
FAD score & 0.189 & 1.208 & $1.069-1.366$ & 0.002 \\
\hline
\end{tabular}

$\mathrm{Cl}$, confidence interval; FAD, family assessment device.

blood pressure control and pregnancy termination are the main principles of the treatment of hypertension during pregnancy. Previous studies have found that pregnancyinduced hypertension is closely related to subjective or objective stress. Zhang et al.'s meta-analysis showed that mental stress significantly increased the risk of preeclampsia during pregnancy (9). In addition, the diagnosis of pregnancy-induced hypertension increases the anxiety and physical symptoms of pregnant women (10).

The median PSS score of the pregnant women in this study was 28 . A cross-sectional study by Sarmasti and colleagues (11) found that the average PSS score of pregnant women with preeclampsia was $35.6 \pm 8.7$, which was significantly higher than that of healthy controls, consistent with the conclusion of this study. Stress not only leads to anxiety, tension, depression, and other negative emotions during pregnancy but also increases adverse pregnancy outcomes. A study of 403 pregnant women undergoing prenatal examination showed that $23.6 \%$ of pregnant women had different degrees of subjective stress symptoms, which were closely related to divorce, separation, mental/physical family trauma, marital disputes, and family disputes (12).

In this study, the average scores of problem-solving and emotional responses in the FAD were $>3$, which was significantly higher than that of normal controls (13). Problem-solving refers to the family's ability to solve problems that threaten family integrity and functional capacity. Based on the McMaster Family Process Model theory, the primary goal and function of the family are to complete daily tasks and deal with crises (14). Most of the patients in this study were primipara. They had no 
experience of coping with pregnancy-induced hypertension, so they may have relied more on their families to deal with this stress. Emotional response evaluates the degree of emotional reaction of family members to stimuli and reflects the emotional communication of family members to the patient. Effective and good emotional responses can help to reduce anxiety, depression, and other adverse mood and improve the level of stress (15).

The pregnant women with pregnancy-induced hypertension were more likely to adopt the "Escape" or "Yield" coping mode, which was consistent with the results of similar studies. For example, women undergoing in vitro fertilization embryo transfer (IVF-ET) scored significantly higher for the "Escape" coping style than the control group, while women with high social support more often adopted the "Face" coping mode (16). In this study, the PSS score positively correlated with the "Escape" and "Yield" coping modes and positively associated with $\mathrm{FAD}$, indicating that the greater the family dysfunction, the more likely patients were to adopt these coping modes.

Univariate analysis showed that education level, average monthly family income, and total score of FAD were independent risk factors of the PSS score. In contrast, multivariate analysis showed that FAD was the independent risk factor of PSS score. We speculate that patients with low education levels may have insufficient knowledge of the disease, while patients with low average monthly family income may worry that adverse pregnancy outcomes will seriously affect the family's financial situation and thus increases the stress level of the pregnant woman with hypertension. Studies have found that education level and family income, and other economic and social status can significantly affect the physical and mental health of pregnant women with preeclampsia (17). The total score of FAD had an independent and significant effect on the PSS score of patients, suggesting that a well-functioning family is helpful for pregnant women to cope with the stressor of gestational hypertension (18).

In conclusion, pregnant women with pregnancyinduced hypertension with high stress levels are more likely to adopt the "Escape" and "Yield" coping modes. Family dysfunction will increase the stress level of pregnant women with gestational hypertension. In clinical or nursing practice, medical staff should incorporate a family function evaluation and other support systems into the nursing plan to help improve the patient's stress level.

\section{Acknowledgments}

Funding: None.

\section{Footnote}

Reporting Checklist: The authors have completed the STROBE reporting checklist. Available at https://dx.doi. org/10.21037/apm-21-2662

Data Sharing Statement: Available at https://dx.doi. org/10.21037/apm-21-2662

Conflicts of Interest: All authors have completed the ICMJE uniform disclosure form (available at https://dx.doi. org/10.21037/apm-21-2662). The authors have no conflicts of interest to declare.

Etbical Statement: The authors are accountable for all aspects of the work in ensuring that questions related to the accuracy or integrity of any part of the work are appropriately investigated and resolved. All procedures performed in this study involving human participants were in accordance with the Declaration of Helsinki (as revised in 2013). The study was approved by the Ethics Committee of Haikou Hospital of the Maternal and Child Health (No. 2018042) and informed consent was given by all the patients.

Open Access Statement: This is an Open Access article distributed in accordance with the Creative Commons Attribution-NonCommercial-NoDerivs 4.0 International License (CC BY-NC-ND 4.0), which permits the noncommercial replication and distribution of the article with the strict proviso that no changes or edits are made and the original work is properly cited (including links to both the formal publication through the relevant DOI and the license). See: https://creativecommons.org/licenses/by-nc-nd/4.0/.

\section{References}

1. Lo JO, Mission JF, Caughey AB. Hypertensive disease of pregnancy and maternal mortality. Curr Opin Obstet Gynecol 2013;25:124-32.

2. Bateman BT, Shaw KM, Kuklina EV, et al. Hypertension in women of reproductive age in the United States: 
NHANES 1999-2008. PLoS One 2012;7:e36171.

3. Roberts L, Davis GK, Homer CSE. Depression, Anxiety, and Post-traumatic Stress Disorder Following a Hypertensive Disorder of Pregnancy: A Narrative Literature Review. Front Cardiovasc Med 2019;6:147.

4. Zheng B, Yu Y, Zhu X, et al. Association between family functions and antenatal depression symptoms: a crosssectional study among pregnant women in urban communities of Hengyang city, China. BMJ Open 2020;10:e036557.

5. Kugler JP, Yeash J, Rumbaugh PC. The impact of sociodemographic, health care system, and family function variables on prenatal care utilization in a military setting. J Fam Pract 1993;37:143-7.

6. Rauchfuss M, Fischer T, Bogner G, et al. Influence of so far neglected psychosomatic factors, BMI and smoking on pregnancy-induced hypertension (PIH). Pregnancy Hypertens 2012;2:93-100.

7. Meng R, Li J, Wang Z, et al. The Chinese version of the Perceived Stress Questionnaire: development and validation amongst medical students and workers. Health Qual Life Outcomes 2020;18:70.

8. He Y, Jian H, Yan M, et al. Coping, mood and healthrelated quality of life: a cross-sectional study in Chinese patients with advanced lung cancer. BMJ Open 2019;9:e023672.

9. Zhang S, Ding Z, Liu H, et al. Association between mental stress and gestational hypertension/preeclampsia: a metaanalysis. Obstet Gynecol Surv 2013;68:825-34.

10. Black KD. Stress, symptoms, self-monitoring confidence, well-being, and social support in the progression of preeclampsia/gestational hypertension. J Obstet Gynecol Neonatal Nurs 2007;36:419-29.

Cite this article as: Xing S, Wan L, Fu A, Liu W, Lin L, Wang C, Wang J, Huang G, Lu M. Correlation analysis of stress and family function and coping modes in pregnant women with pregnancy-induced hypertension syndrome. Ann Palliat Med 2021;10(11):11688-11694. doi: 10.21037/apm-21-2662
11. Sarmasti N, Ayoubi SH, Mahmoudi G, et al. Comparing Perceived Social Support and Perceived Stress in Healthy Pregnant Women and Pregnant Women with Preeclampsia. Ethiop J Health Sci 2019;29:369-76.

12. Thongsomboon W, Kaewkiattikun K, Kerdcharoen N. Perceived Stress and Associated Factors Among Pregnant Women Attending Antenatal Care in Urban Thailand. Psychol Res Behav Manag 2020;13:1115-22.

13. Wang J, Zhao X. Perceived family functioning in depressed Chinese couples: a cross-sectional study. Nurs Health Sci 2013;15:9-14.

14. Barney MC, Max JE. The McMaster family assessment device and clinical rating scale: questionnaire vs interview in childhood traumatic brain injury. Brain Inj 2005;19:801-9.

15. Farber MJ, Romer AL, Kim MJ, et al. Paradoxical associations between familial affective responsiveness, stress, and amygdala reactivity. Emotion 2019;19:645-54.

16. Shen L, Xing L. Analyses of medical coping styles and related factors among female patients undergoing in vitro fertilization and embryonic transfer. PLoS One 2020;15:e0231033.

17. Ross KM, Dunkel Schetter C, et al. Socioeconomic Status, Preeclampsia Risk and Gestational Length in Black and White Women. J Racial Ethn Health Disparities 2019;6:1182-91.

18. Thadhani RI, Johnson RJ, Karumanchi SA. Hypertension during pregnancy: a disorder begging for pathophysiological support. Hypertension 2005;46:1250-1.

(English Language Editor: K. Brown) 